\title{
NUEVAS REALIDADES EN MATERIA VOCACIONAL
}

DOI: https://doi.org/10.52039/seminarios.v62i218.106

AMEDEO CENCINI ${ }^{*}$

El paso de Jesús por la orilla del mar de Galilea y la llamada que dirige a los primeros discípulos marca el nacimiento de la pastoral vocacional. En rigor, nace con este primer anuncio (aunque el Primer Testamento abunde en historias vocacionales). No obstante, podemos decir, que la pastoral vocacional es un fruto reciente de un tiempo de crisis en que ha comenzado a perfilarse, sobre todo en países de antigua cristiandad, la posibilidad o fantasma de una contracción numérica de la vocación presbiteral tan relevante como para poner en peligro un servicio pastoral adecuado a la necesidad de la comunidad creyente. La pastoral vocacional nace, pues, en un momento de crisis y miedo, incluso de angustia (jangustia vocacional!). No debemos olvidarlo.

Asimismo, vivimos hoy un tiempo particularmente singular en que, por un lado, advertimos una fuerte exigencia de novedad, impulsados por el soplo del viento impetuoso del papa Francisco, de Evangelii gaudium, de la nueva evangelización; $y$, por otro, nos frena el miedo que hemos mencionado, que no es en absoluto buen consejero.

Por todo esto, no podemos perder de vista la referencia a la acción vocacional de Jesús, el primer sembrador vocacional. Cualquier camino novedoso en este terreno será auténtico en la medida en que remita al estilo de Jesús; por tanto, no lo es aquella pastoral vocacional que reacciona tan sólo al miedo que ve peligrar la propia supervivencia, o sea, que esté guiada por esa «angustia vocacional presbiteral» que, como bien sabemos, no produce vocaciones sino más angustia. $Y$ mejor que no produzca vocaciones, pues serían vocaciones de sacerdotes jangustiados y angustiantes!

Junto a esta constatación, la otra referencia que actúa como brújula de esta reflexión es el tema del próximo Sínodo: «Los jóvenes, la fe y el discerni-

* Amedeo Cencini (Italia, 1948). Sacerdote canosiano. Profesor de pastoral vocacional y de metodología de la dirección espiritual en la Universidad Salesiana de Roma, y de formación para la madurez afectiva en el curso de formadores de la Universidad Gregoriana (Roma). Desde 1995 es consultor de la Congregación para los Institutos de Vida consagrada y las Sociedades de vida apostólica. 
miento vocacional», que ha de ser entendido - según la nota vaticana-como una invitación a la comunidad eclesial (quizás, en particular, a la presbiteral) a «acompañar a los jóvenes en el camino de su existencia hacia la madurez, de modo que, mediante un proceso de discernimiento, puedan descubrir su proyecto de vida y realizarlo con alegría, abriéndose al encuentro con Dios y con los hombres y participando activamente en la edificación de la Iglesia y la sociedad» ${ }^{1}$.

Además, para hablar de nuevas realidades en el campo vocacional se necesita un conocimiento general de todo aquello que está sucediendo en la Iglesia. Por este motivo, mi intención no es la de llevar a cabo una presentación puntual de nuevas experiencias y metodologías en este campo, sino reflexionar sobre nuevas realidades vocacionales a partir de la nueva cultura vocacional que se está abriendo paso en la Iglesia (y habría que confrontar con la del pasado). Esta opción arranca del siguiente principio: la pedagogía es la concreción operativa del camino de un determinado sujeto o realidad hacia la propia identidad. Por tanto, la pedagogía vocacional (o de la animación vocacional), está estrechamente relacionada con el punto de llegada, la naturaleza de la vocación en términos teológicos: ella es la que inspira y guía la metodología vocacional, impulsándola eventualmente hacia nuevas modalidades de acción. Estas, por su parte, crecerán en evidencia y estabilidad en la medida en que se apoyen y estén motivadas por una originaria y auténtica visión teológica. Precisamente por ello, muchas novedades en materia de animación vocacional se han revelado pasajeras y apenas han dejado huella.

Trataré de moverme, en suma, considerando un doble frente, teológico y pedagógico (que denominaré «modalidades de acción»), y proponiendo algunos signos teórico-prácticos de novedad desde diversos puntos de vista.

\section{TeOlogía de la pastoral Vocacional}

La pastoral vocacional ha sido considerada habitualmente como una pastoral muy funcional y práctica, con poco espesor teológico, nacida en época de vacas flacas y orientada a un objetivo más bien inmediato: el aumento de las vocaciones al sacerdocio. De hecho, entre los diversos secretariados o delegaciones de una curia diocesana, a menudo el de la pastoral vocacional no sólo es el último que ha sido constituido en el tiempo, sino que incluso en algunos casos se encuentra vinculado a otros departamentos (como el de pastoral juvenil) o está dirigido por quien, por ejemplo, trabaja en la formación sacerdotal.

1. Papa: un Sinodo su giovani e fede, nota vaticana in commento allindizione della XV Assemblea Generale Ordinaria del Sinodo dei Vescovi (cf. Avvenire, 7.X.2016). 
Sin embargo, la pastoral vocacional posee una identidad propia, fundamentalmente teológica, que le proporciona una razón de ser que va más allá de un objetivo meramente funcional o cuantitativo. Esta afirmación ha venido adquiriendo una evidencia cada vez mayor en los últimos años. Hemos descubierto que la pastoral vocacional posee su propia teología y su objeto, tanto material como formal; con una imagen específica de Dios como el Eternamente Llamante, y del hombre como el llamado en todo momento, es decir, como ser ob-audiens, siempre a la escucha: pues en la vida no existe un momento vocacional único, sino que todo instante esconde y contiene una llamada. Es en este ser llamado por Dios donde el hombre reencuentra su propia dignidad. Más aún, se trata de una teología con un específico objeto de interés como es el discernimiento, en el tiempo, del proyecto original sobre una criatura; una teología con su propia categoría interpretativa de la Palabra: la vocación; una teología que considera la vida una llamada constituida esencialmente por una serie de llamadas que culminan en la muerte, o llamada por excelencia; una teología para la que las situaciones más complejas y difíciles (una enfermedad, un sufrimiento, una injusticia...) contienen una llamada y se leen en clave de llamada.

\section{Modalidades de acción}

\section{a) Llamada constante}

Pongamos un ejemplo que permite entrever una modalidad concreta de acción: hace tiempo se acostumbraba a invitar a la persona que sufría por diversos motivos, a ofrecer el propio sufrimiento por las vocaciones al sacerdocio. Un gesto que era y es encomiable y que puede seguirse sugiriendo a condición de que no se olvide esa otra perceptiva de mayor arraigo teológico y más eficaz desde el punto de vista pedagógico, además de ser más respetuosa con la persona y su situación concreta. Porque ¿acaso no esconde el sufrimiento una llamada, es decir, no puede proponerse como vocación actual de la vida de la persona, como modo de responder a un proyecto misterioso de Dios? ¿No tiene el creyente que atraviesa el momento de la prueba el derecho de ser ayudado por la Iglesia a descubrir esa misteriosa llamada inscrita en la prueba?

\section{b) El evangelio de la vocación}

Así pues, la pastoral vocacional implica una reflexión teológica de la que ha de alimentarse continuamente para mantener activo el evangelio de la vocación como buena noticia acerca de Dios y del hombre, y no degenerar en técnica y formas de reclutamiento que tergiversarían su sentido y lo empobrecerían. De hecho, lo que entendemos por pastoral vocacional resulta mucho más eficaz y convincente cuando se entiende y motiva a partir de estos presu- 
puestos teológicos. Conviene recordar, además, que una pastoral vocacional entendida así tiene su propia razón de ser entre las diversas áreas del trabajo pastoral, no es la cenicienta. Se encuentra vinculada a la pastoral de la familia y de la juventud, e implícitamente con todos y cada uno de los ámbitos de la pastoral general ordinaria, como veremos más adelante. El trabajo de los últimos años ha llevado a las diversas conferencias episcopales a dotarse de un servicio o centro nacional para las vocaciones, así como a las diócesis (no todas, es verdad) a crear una delegación o secretariado diocesano de pastoral vocacional que en no pocas ocasiones representa bien la realidad vocacional diocesana, y en otras se concibe vinculado de manera específica a la pastoral vocacional del seminario.

\section{VOCACIONES DE LA PERIFERIA}

Todos sabemos que el flujo vocacional se está desplazando de manera creciente desde zonas de antigua evangelización hacia aquellas otras que se han abierto más recientemente al mensaje evangélico. Lo que quiere decir, hablando en general, que allí donde se evangeliza o donde el anuncio resuena en su novedad y radicalidad es más probable que nazcan vocaciones. Cuando el adolescente o el joven se encuentra con el mensaje evangélico aún siente una fascinación indiscutible. Como señala el papa Francisco, «donde hay vida, fervor, ganas de llevar a Cristo a los demás, surgen vocaciones genuinas $»^{2}$.

Dicho de manera negativa: la crisis vocacional también es consecuencia de una pastoral repetitiva y mediocre, o fruto de un proceso de asimilación cultural del mensaje cristiano que le resta mordiente y capacidad de sorprender y poner en tela de juicio la realidad. Una vez más, según el Papa, «en muchos lugares escasean las vocaciones al sacerdocio y a la vida consagrada. Frecuentemente esto se debe a la ausencia en las comunidades de un fervor apostólico contagioso, lo cual no entusiasma ni suscita atractivo» ${ }^{3}$. Esta es la perspectiva de una Iglesia en salida.

Pero cabe prestar atención a otro aspecto digno de consideración acerca del origen de las vocaciones. Podemos afirmar que cada vez más proceden de las periferias del mundo y de la Iglesia. El ámbito de procedencia de las vocaciones está cambiando: ya no son sólo los «nuestros» los que se deciden por el seguimiento (individuos que han sido acólitos, hijos de buenas personas, creyentes o hijos de creyentes desde hace generaciones); sino que muchos proceden de situaciones no propicias o periféricas, tanto respecto de

2. Papa Francisco, Evangelii gaudium, 107.

3. Ibid. 
la Iglesia como del mundo. En el fondo, Jesús llama a personas que no están en el Templo, es decir, entre los adeptos al culto; más bien ha elegido como discípulos a pecadores -como Mateo y Judas- de un pueblo de pecadores, enviándoles no a los justos, sino a los pecadores.

\section{Modalidades de acción}

\section{a) De todo lugar y condición}

Todo ello apunta a una modalidad de acción correspondiente que se inspira, para entendernos, en el icono evangélico del sembrador, cuyo gesto amplio esparce la semilla de la vocación en todo tipo de terreno, desde el camino a la tierra plagada de zarzas, allá donde menos cabría esperar una respuesta vocacional. La enseñanza resulta evidente y pone en crisis toda aquella pastoral vocacional tímida y miedosa que se limita a frecuentar lugares seguros, que se despliega a la sombra del campanario, en medio de personas cercanas o más prometedoras; que carece del coraje de radicarse en ambientes nuevos porque considera que no merece la pena; que no se deja movilizar, en suma, por la certeza de que es Dios quien llama a todos y cada $u_{n}{ }^{4}$. Una pastoral vocacional que es tímida, aunque al tiempo presuntuosa y poco creyente, pues decide originariamente delimitar los espacios de su anuncio, haciéndose por ello poco inteligente y auto-perjudicial al excluir arbitrariamente del diálogo vocacional ambientes y personas. Cuántas veces nos hemos lamentado y nos lamentamos de la pobreza de la respuesta vocacional, sin darnos cuenta de que somos nosotros mismos quienes hemos dirigido la llamada a una pequeña minoría de personas como si Dios no llamase a todos, o peor aún, como si fuésemos nosotros quienes decidimos quién puede ser llamado y quién no.

\section{b) «Nadie nos ha llamado»}

Cuántos jóvenes podrían exclamar como los trabajadores de la última hora: « ¡Nadie nos ha llamado!» (Mt 20,7). Habríamos de recordar el reclamo de Pablo VI: «Que nadie, por culpa nuestra, ignore lo que debe saber para orientar, en el mejor sentido posible, la propia vida». Y aun así, jcuántos jóvenes no ha escuchado nunca propuesta cristiana alguna acerca de su vida y su futuro! En realidad, es una gran mayoría la que no ha sido llamada nunca por nadie. Por otra parte, aprender a sembrar la buena semilla de la vocación en todo lugar y condición, en todo corazón y ambiente, como sucede ya en algunos contextos eclesiales, haría (como ya sucede, en verdad) nacer una nue-

4. Conviene recordar que «lo contrario del amor no es el odio, es el miedo» (Katherine Pancol). 
va pedagogía vocacional, provocaría la búsqueda de nuevas modalidades comunicativas, nos obligaría a ser creativos y valientes a la hora de afrontar nuevos contextos y culturas, generando finalmente nuevas vocaciones para nuevos y antiguos ministerios.

\section{EL EXTRAÑO FENÓMENO DE LA SELECCIÓN ADVERSA}

Además, hemos de señalar, con mucho realismo, que no siempre la calidad de las vocaciones responde hoy a un estándar elevado, sino que en ocasiones, y aunque no sea agradable reconocerlo, encontramos personas de escasa calidad. Es el fenómeno de la llamada selección adversa que considera en primer lugar, más allá de los (posibles) llamados, la calidad de la vida y el testimonio de los llamados o, más en concreto, de nuestras comunidades presbiterales y religiosas. Esta ley sociológica afirma que cuando esa calidad es baja, la institución atrae a los mediocres, que no la cuestionarán. Es una constatación amarga pero real, y confirmada por los hechos: la mediocridad llama a los mediocres. La mediocridad posee una fuerza notable, tiende a reproducirse atrayendo y generando, de alguna manera, a los mediocres. Estos garantizan la continuidad de una institución en el tiempo, pero la hacen más mediocre en cuanto favorecen la pérdida de ese espíritu de donación radical que es propio de la llamada que procede de lo alto.

\section{Modalidades de acción}

a) Más alta y más atrayente

La lección que se extrae de este fenómeno de la selección adversa es que la pastoral vocacional ha de ser construida a partir de un testimonio auténtico, personal y comunitario; de modo que no cabe adoptar una actitud de renuncia al mismo. En estos últimos años se ha revelado muy real el riesgo de rebajar la calidad de las vocaciones. En tiempo de vacas flacas se cierne el peligro de hacer rebajas, de promover a todos, de descuidar el discernimiento, de no exigir demasiado, pasando a veces por alto situaciones verdaderamente problemáticas desde el punto de vista de la integridad psicológica y moral, llegando a promocionar, he hecho, a los menos indicados. Pensemos, por ejemplo, en el fenómeno negativo del «turismo vocacional» por parte de aquellos que han sido excluidos de un seminario o un instituto

5. La intuición de la selección adversa se debe a un economista, el premio Nobel G. Akerlof, que demostró que, en muchas situaciones, el mercado no premia a los mejores, sino que en la medida en que carece de dirección, tiende a atraer y seleccionar a los peores o, en sus propias palabras, a los lemons, es decir, a los «bobos» (L. Bruni, «Voglia di politica», en Avvenire, 18.11.2011). 
y vagan de una diócesis o congregación a otra hasta que encuentran... su nido, con escasa probabilidad de hallar la propia paz (o de poder brindársela a los otros). Lo más grave de este fenómeno reside, sin duda, en la actitud consentidora de superiores y formadores para con estas personas, pensando que así contribuyen a resolver el problema de la escasez numérica (haciendo oídos sordos de las disposiciones canónicas al respecto) ${ }^{6}$. Este es el peor modo de resolver los problemas de la crisis vocacional. Y no hablamos sólo de lo que se refiere a la formación en sus varias fases de discernimiento, sino al modo mismo de hacer pastoral vocacional. Resulta iluso pensar que se es atractivo haciendo que todo sea más fácil; la psicología nos dice todo lo contrario: es la grandeza del ideal la que ejerce poder de atracción sobre el ánimo del hombre.

\section{b) Cuanta más donación, más exigencia}

No estamos diciendo que se exija el imposible de tornar a viejas y radicales formas ascéticas de dudoso gusto (ensombrecidas a veces por cierta ambigüedad perfeccionista-moralista de fondo), sino de reconocer que en la actualidad las instituciones religiosas dotadas de poder de atracción vocacional parecen aquellas que subrayan con mayor nitidez el ideal evangélico y su ascendente sobre el corazón humano. Los jóvenes tienen necesidad de esas propuestas potentes, como la del Evangelio y su fuerza inigualable, que conjugan don y exigencia, que dan el máximo y, al mismo tiempo, exigen todo, por las que merece la pena gastar la vida. A la percepción-descubrimiento de que sólo Dios puede dar respuesta al corazón humano, se une el desafío y la propuesta de amar con el corazón de Dios. Amar a Dios con corazón de hombre y amar al hombre con corazón divino. He aquí lo que atrae vocacionalmente. «Los cristianos no hemos sido elegidos por el Señor para pequeñeces. Id siempre más allá, hacia las cosas grandes. Poned en juego vuestra vida por los grandes ideales... pido que orientéis la pastoral vocacional en esta dirección, acompañando a los jóvenes por itinerarios de santidad que, al ser personales, exigen una auténtica pedagogía de la santidad ${ }^{7}$.

Las medidas a medias atraen temporalmente, pero al final desilusionan y no colman la sed del corazón, resultan insuficientes para dar sentido a la existencia. Hacer una propuesta que se ubique por debajo de aquello que el corazón del hombre puede ofrecer y acoger, significa no sintonizar con su

6. Un fenómeno paralelo es el del reclutamiento vocacional en países foráneos, que suele despreocuparse de los parámetros del discernimiento. De ello habla con frecuencia el propio papa Francisco: «Aunque la constitución de comunidades internacionales y multiculturales ponga de manifiesto la universalidad del carisma, hay que evitar en modo absoluto el reclutamiento de candidatas de otros países con el único fin de salvaguardar la supervivencia del monasterio» (Vultum Dei quaerere, $3, \S 6$ ).

7. Mensaje para la Jornada mundial de oración por las vocaciones 2014, 4. 
expectativa más profunda y, en consecuencia, no puede provocar adhesión vocacional alguna. De igual modo, las propuestas unilaterales que subrayan sólo un aspecto de la proposición vocacional (bien como don de lo alto, bien como aspiración del corazón humano) se revelan débiles y con escasa capacidad de motivar una decisión. El joven elige a la luz de la percepción de un don, y cuanto más grande sea el don, mayor es la responsabilidad frente a él o la sensación de una respuesta que ha de ser total.

Hemos de hacer un profundo examen de conciencia sobre la calidad de nuestro testimonio, individual y comunitario. La única, verdadera y más grande catástrofe no es la disminución numérica, sino la mediocridad espiritual ${ }^{8}$. Expresándome en clave más positiva, y como reacción a dicha mediocridad, hago referencia tan sólo a un par de aspectos en perspectiva vocacional. Por una parte, resulta fundamental el testimonio de una cierta «fraternidad» presbiteral o religiosa que dé testimonio de una santidad comunitaria ( $\mathrm{y}$ no como propiedad excepcional de un individuo); testimonio que, por su naturaleza, tiene más impacto en el ánimo del joven y se convierte en fuerza de atracción vocacional. Por otro lado, también es fundamental que el sacerdote o el consagrado se muestre contento de su vocación y la sienta como una realidad bella que procura belleza y sabor a la propia vida, como una opción que da cuenta de por qué aquel amor llena su corazón, como una respuesta de donación total ante una llamada que solicita la total donación de sí ${ }^{9}$.

\section{EL SENTIDO FUNDAMENTALMENTE VOCACIONAL DE LA VIDA}

En el pasado era frecuente insistir en una pastoral vocacional donde la llamada tenía como modelo de referencia ser un héroe 0 , al menos, un aspirante a héroe. La concepción de llamada que había detrás guardaba relación con lo extraordinario, es decir, únicamente algunas personas estaban capacitadas para escucharla. En realidad se trata de una modalidad comunicativa de la vocación que es muy débil, porque se expone con mucha facilidad al rechazo subjetivo de quien no se siente héroe o cree que debe (no sólo puede) ajustarse a algo menos exigente; y porque, digámoslo una vez más, el anuncio

8. Esa es la que se encuentra, recurriendo a un ejemplo quizás un poco insólito, en la raíz de los escándalos sexuales (cf. A. Cencini, ¿Ha cambiado algo en la lglesia después de los abusos sexuales?, Sígueme, Salamanca 2016).

9. Los jóvenes se dan cuenta de manera inmediata cuándo Dios ocupa el centro de la vida y los afectos del sacerdote. El siguiente episodio es prueba de ello. Un sacerdote es trasladado y el joven, responsable del grupo juvenil, se acerca a saludar y le dice: «Quiero darte las gracias». El sacerdote esperaba las gracias por todas las iniciativas que habían puesto en marcha y compartido juntos. Pero el joven continua: «Te quiero agradecer que al pasar todos los días por la iglesia, te he visto con el evangelio en las manos haciendo tu lectio divina. Tu nos has ofrecido catequesis estupendas, pero no me has evangelizado tanto como cuando te he visto a la escucha de la Palabra de Dios». 
vocacional se dirige sólo a aquel, no a todos, que se siente subjetivamente atraído de alguna manera. En realidad la vocación, cristianamente entendida, no se concibe como algo extraordinario que sólo algunos elegidos pueden atender, puesto que se construye sobre un sentido o gramática elemental de la vida, que toda persona puede entender: la vida es un bien recibido que tiende por naturaleza a convertirse en un bien donado. Este es el sentido de la vida, que es fundamentalmente vocacional. Si la vida es un don recibido (ningún ser humano ha tenido que aprobar un curso para existir), el don tiende por su propia naturaleza a convertirse en don, es decir, llega a ser un bien que se dona cuando la persona se hace adulta. Se trata de un principio objetivo, válido y verdadero para todos. Y es importante fundar objetivamente el dato vocacional, porque sólo así se puede hacer una propuesta verdaderamente universal, que alcanza a todos, al menos potencialmente.

\section{Modalidades de acción}

\section{a) No se necesitan héroes}

De todo ello se deriva una modalidad de anuncio vocacional más eficaz y convincente. De hecho, la pastoral vocacional ha adquirido mayor conciencia de que este punto de partida se revela más capaz de llegar a todos al fundarse sobre el sentido más elemental de la existencia humana: nadie está al margen de esta lógica, de esta verdad de la vida. Es más, el joven debe saber, y hay que recordárselo con insistencia, que es libre de tomar la opción que considere, pero no es libre de escapar a esa lógica del don. Si lo hiciese estaría eligiendo el propio mal, entraría en contradicción consigo mismo y, deformando su vida, ¡no sería feliz!

Luego no es necesario ser un héroe para hacer una opción vocacional (la misma lógica del héroe apenas tiene impacto en la sensibilidad juvenil inmersa en la actual cultura de la mediocridad); basta con advertir el auténtico sentido de la vida, en la conciencia de que uno sólo es feliz si respeta la verdad de sí. De ahí que toda catequesis elemental que incida en el significado de la existencia terrena como lógica del don que se recibe y se dona, sea por sí misma motivo de animación vocacional. Lo verdaderamente decisivo es mostrar la evidencia invencible del nexo que vincula la percepción del don con la decisión de darse a sí mismo.

En otras palabras, que tomamos de un documento pontificio: «Si hay un don al comienzo de la vida del hombre, que lo constituye en ser, entonces la vida tiene el camino trazado. Y si es don, será plenamente él mismo sólo si se realiza en la perspectiva del darse; será feliz a condición de respetar esta naturaleza suya... será libre de elegir la orientación específica que quiera, pero no será libre de pensarse fuera de la lógica del don... Si se admite esta ver- 
dad antropológica, entonces se puede hacer cualquier propuesta vocacional. También, entonces, la vocación al ministerio ordenado o a la consagración religiosa o secular, con toda su carga de misterio y mortificación, llega a ser la plena realización de lo humano y del don que cada hombre tiene y es en lo más profundo de su ser» ${ }^{10}$.

\section{b) De la gratitud a la gratuidad}

Así pues, se necesita favorecer aquel conjunto de actitudes vocacionales virtuosas que se inspiran en la gratitud, en la conciencia de haber recibido un gran don sin haber hecho nada para merecerlo, en la convicción humilde e inteligente de que darse es lo mínimo que puede uno hacer, siendo consciente de que, aunque el hombre se dé a la vida, a los otros y a Dios, jamás podrá corresponder con el bien recibido.

Más en concreto, hay que promover actividades formativas que procuren al joven hacer experiencia de que el don de sí es natural y hermoso, mucho más que ser virtuoso, porque afirma la verdad del ser humano.

\section{c) Colaboración pastoral y "via pulchritudinis»}

Estamos necesitados de un profundo espíritu de colaboración entre diversos sectores de la pastoral en clave de sinergia propositiva; por ejemplo, entre pastoral juvenil, familiar y vocacional (quizá aprovechando oportunidades como las Jornadas mundiales), entre diversos ámbitos relacionados con la pastoral vocacional, como el de la caridad y la misión. Esta convergencia es muy importante para contrarrestar el influjo de la actual «cultura egocéntrica e individualista» que, por tendencia natural, se contrapone al camino vocacional como servicio y salida de uno mismo.

En estos últimos años se ha trabajado mucho, a nivel de propuestas nacionales, en el lanzamiento de la «via pulchritudinis» como magnífico camino vocacional: el arte, la literatura, la música y el cine constituyen un gran recurso de lenguajes nuevos y comunicativos, capaces de interceptar los anhelos y preguntas que anidan en el corazón de los jóvenes, así como de mediar un anuncio vocacional más vivaz y creativo ${ }^{11}$.

Catequesis y liturgia son sectores que podrían estar explícitamente involucrados en este testimonio de la belleza de la fe y el misterio, de la vida creyente y del ser llamado. La belleza podría ser el denominador común o punto de convergencia de esta colaboración pastoral entre los diversos sectores y ámbitos.

10. Obra pontificia para las vocaciones eclesiásticas, Nuevas vocaciones para una nueva Europa, Roma 1998, 36b.

11. Sugiero aquí mi trabajo Llamados a la belleza, una pedagogía vocacional, Paulinas, Madrid 2016. 
d) Pastoral generativa ${ }^{12}$

Otra relativa novedad en términos de pastoral vocacional consiste en la llamada pastoral generativa. Significa ser pastores con ojos y oídos atentos a los acontecimientos humanos que acaecen hoy, a veces trágicos e inquietantes, que interpelan a la comunidad creyente y esperan de ella una implicación y una respuesta, tal vez no obvia o repetitiva; atentos a los carismas y dones que atesoran las personas, a las potencialidades más que a los límites, al presente y al futuro más que al pasado, a una Iglesia que reencuentra el profundo sentido de la koinonía, de la diakonía y de la martiría (o comunión en la oración litúrgica; el testimonio de la Palabra que se dona; el servicio gratuito y desinteresado de la caridad), que vive no para su bienestar psicológico o espiritual, sino en clave de don para el mundo que trata de hacer comprensible y gozable incluso al no creyente, a quien invita a tomar parte en esa dinámica de donación.

En síntesis, una pastoral no puede ser sólo conservadora y garantizar el statu quo, sino que ha de mirar adelante y generar nuevos contactos, nuevos creyentes, nuevos ministerios, nuevas vocaciones... Porque el mundo lo exige. Este modo pastoral de situarse frente al mundo supone para la Iglesia una profunda creatividad y generatividad vocacional.

\section{Del MOdeLo de LA CREACIÓN AL MOdELO dE LA REDENCIÓN}

Otro espacio en que está aconteciendo un cambio significativo -con implicaciones en la modalidad pedagógica de la pastoral vocacional- es el relativo al modelo teológico adoptado. Hasta ahora se hacía referencia sustancialmente a la creación. De acuerdo con este modelo, la vocación del hombre consiste en un proyecto pensado por Dios, o en la realización de un proyecto original a la luz de ese pensamiento «primitivo», si podemos hablar así, según el cual el Padre Creador ha modelado a cada criatura poniendo en ella un trazo de la propia imagen y semejanza. En el modelo de la redención, en cambio, la vocación se entiende como una llamada que dirige el Padre Redentor a todo hombre salvado por la sangre del Hijo; no sólo para

12. La "pastoral generativa» (o d'engendrement en francés) es una nueva forma de animar los modelos pastorales ya existentes y de promover un nuevo «estilo» de vida y acción, inspirado en el Evangelio, un modo nuevo de ser y de relacionarse en medio de un mundo que está en continua transformación y que ya no es cristiano, sino secularizado y posmoderno. Esta forma de considerar la cultura actual no se nutre de nostalgias ni se desarrolla en términos de «seguridad» o de «crisis», es decir, no está marcado en absoluto por el derrotismo pastoral, sino que se revela propositivo y creativo mediante la invención de un modelo a partir de la situación cultural, como se ha hecho en otras etapas de la historia. Su punto de partida es la cultura del presente en su totalidad sin prescindir de ella, o mejor aún, sin restarle valor. 
que se abrace a la salvación que ha obtenido el Hijo, sino también con vistas a que elija colaborar activamente en el proyecto de la salvación de manera responsable y en beneficio de otros, imitando así por gracia a Aquel que ha dado su vida por la salvación de la entera humanidad. Creación y redención, en suma, son los dos polos clásicos del concepto (o misterio) de vocación: uno más estático y contemplativo, el otro mucho más dinámico y activo; el primero como expresión del ser humano en sí, el segundo del ser humano en relación, el primero más tradicional, aunque expuesto al riesgo de una interpretación subjetivo-narcisista; el segundo modulado por la conformación a Cristo y la solidaridad con el otro, más provocador y significativo para la cultura del presente (dada su inercia narcisista), más capaz de señalar un modelo de ser hombre adulto en Cristo.

La novedad reside en que la teología actual parece reflexionar con más insistencia en este segundo aspecto de la vocación, que quizás apunta a una dimensión inexplorada de la identidad de la persona llamada. Con ello se afirma que la vocación cristiana no está en función del individuo y de sus economías espirituales, tampoco de su salvación y de su santidad privada o su paraíso futuro, sino que es una llamada a preocuparse de los otros, a sentirse responsable de la salvación del otro; a convertirse en mediación de la voz del Hijo, que continúa llamando para que otros puedan escucharlo y responder. Tampoco puede ser entendida -y es este un error bastante extendido-como banal autorrealización del sujeto, lo que constituiría un sinsentido no sólo teológico, sino también psicológico. De igual modo que nadie puede dar al hombre lo que únicamente Dios puede, nadie puede pedir al hombre aquello que únicamente Dios le puede pedir: entrar de forma activa en el drama de la redención. Ahora bien, nada como la vocación cristiana tiene el poder de hacer al hombre adulto, extrovertido, interesado en la vida y en la salvación del otro. ¡lgual que Dios!

En este sentido, la vocación puede ser considerada el punto más alto de una auténtica teología en cuanto reflexión humana sobre el Dios Creador y Redentor. Es el indicador de hasta qué punto ha hecho Dios al hombre semejante a sí mismo, es decir, agente de salvación, capaz de salvar, por medio de la gracia, claro está.

Podemos así comprender también que entre las diversas vocaciones exista al mismo tiempo igualdad y diferencia: todas están al servicio de la salvación, aunque cada una de manera particular. Y si bien todas poseen la misma dignidad, es el tipo de participación en el drama de la redención la que les otorga su cualidad. Todas son, en fin, igualmente dramáticas, porque todas están en función de la salvación y la salvación del otro. Aquí reside la medida más alta de la vida cristiana ordinaria y la originalidad de la idea cristiana de vocación que se propone a todos y no está al servicio de la propia persona, sino de la redención del hermano. 


\section{Modalidades de acción}

a) De la gramática al sentido dramático de la vida y la salvación

De esta idea nace un nuevo tipo de propuesta pedagógica que se construye en torno a una lógica típicamente cristiana de apertura relacional y responsabilidad por el otro. De modo que la referencia ya no es la lógica subjetiva del "si quieres y te apetece...», o de la autorrealización, ni siquiera de de la necesidad de la Iglesia o los problemas del mundo; en definitiva, la lógica de todos aquellos modos de proponer la vocación que son débiles, frente a los que el sujeto puede decir fácilmente: «Sí, es interesante, pero no es para mí, yo me siento orientado en otra dirección».

Incluso vuelve aquí de algún modo la lógica mencionada en el parágrafo precedente al señalar que la propuesta vocacional se funda en una gramática elemental de la vida (como don recibido que tiende por su naturaleza a convertirse en un bien que se dona). Ahora vemos esta misma lógica en el ámbito del proyecto de la salvación y su cumplimiento dramático; salvación que es don absolutamente inmerecido y gratuito, y hace del salvado actor de salvación. También aquí se trata de un dato objetivo frente al cual el creyente o el joven viandante de la fe percibe toda la belleza dramática de la misma y, además, la propia dignidad de persona que ha sido liberada (o sea, salvada) y es responsable de la salvación del otro (capaz de preocuparse de la redención del otro).

\section{b) Pastoral de la responsabilidad}

De aquí derivan dos aplicaciones en torno a la modalidad de la pastoral vocacional. La primera: quien se decide hoy por la animación vocacional constata que una mayor atención a esta responsabilidad por el otro vinculada a la fe favorece una presentación del cristianismo más convincente y eficaz, más actual y moderna, que termina por suscitar mayores adhesiones en un amplio espectro vocacional. Esa atención reacciona frente a una pastoral del bienestar psicológico, del esteticismo pseudo-espiritual o del interés espiritual exclusivamente individual que, por definición, es una pastoral anti-vocacional. Pensemos, por ejemplo, en la necesidad que se percibe hoy en el joven creyente, a la luz de esa sensibilidad vocacional distinta, de madurar una opción vital de compromiso en lo social o lo político, entendido como gesto de responsabilidad ante los otros y, por tanto, en cuanto creyente (y no por carrera, dinero, fama o bienestar). O pensemos en cómo la propia vocación sacerdotal o religiosa podría experimentar un nuevo impulso motivacional (y purificarse) a partir de este valor de la responsabilidad moral ante los otros, como salvación que se obtiene no primariamente por sí mismo, sino a través de los otros ${ }^{13}$. 83-84.

13. Cf. A. Cencini, Non contano i numeri. Costruire cultura vocazionale, Milano 2011, 
La segunda consecuencia en torno a la modalidad pedagógica revierte sobre la pastoral considerada en general. Es evidente que el paso del modelo de la creación al de la redención conlleva una actitud mucho más provocativa y responsable en lo que toca a la proposición general de la fe cristiana. Puesto que no puede darse solicitud vocacional o descubrimiento de la propia vocación en el seno de una pastoral... del analgésico o de la estética, que parece haberse olvidado del «alto precio de la gracia» ${ }^{14}$, y se presenta totalmente concentrada en una individualidad subjetiva autorreferencial y un tanto infanti ${ }^{15}$.

Nos referimos a un horizonte vocacional que se conjuga y se actualiza en la perspectiva de una nueva evangelización, encaminada a superar dinámicas repetitivas que suelen revelarse ineficaces (recomendamos aquí una lectura en continuidad entre Nuevas vocaciones para una nueva Europa y Evangelii gaudium).

\section{KERIGMA VOCACIONAL}

Normalmente, la animación vocacional se ubica al final de un camino de educación en la fe; dicho de otro modo, primero se forma al creyente y después al llamado, dado que la llamada se percibe como culmen o expresión de la plena madurez del creyente y signo de una fe adulta. Esta perspectiva es correcta, pero no exclusiva, es decir, el orden entre esos dos momentos (fe y propuesta vocacional) no se articula rígidamente, sino que se puede invertir. Lo que quiero decir es que la propuesta vocacional puede, y tal vez debe, formar parte del primer anuncio, de la acción de mostrar la evidencia de la

14. Cf. D. Bonhoeffer, El precio de la gracia. El seguimiento, Sígueme, Salamanca ${ }^{7} 2016,24-26$.

15. «Existe un infantilismo espiritual que se ha difundido actualmente con diferentes formas, las cuales muestran la huida de la responsabilidad en lo que respecta a Dios, a los demás y, en último término, a uno mismo. Existe una pastoral de los sacramentos que termina por reducirse a la lógica del usar y tirar, aquejada de una desconcertante desproporción entre superproducción (ritual) de bienes de salvación y una efectiva experiencia de la misma. Cuántas misas, oraciones, ritos y sacramentos se multiplican en torno al individuo sin conseguir estimular una conciencia misionera; cuánta gracia, Palabra de Dios y bienes espirituales se encuentran secuestrados por creyentes particulares, individualistas impenitentes; $y$, sobre todo, cuánta mentalidad sobre el ser cristiano se concentra en observar (ciertos preceptos), no cometer (transgresiones) y celebrar (cultos) por sí mismo. Qué poco capaces somos de difundir la idea de que aquel que ha sido salvado por la cruz de Cristo debe convertirse en actor de salvación, según un proyecto de vida específico y responsable. Qué poco crédito damos a la idea de que ser amados por Dios no implica tan sólo lograr una seguridad que consuela, sino que significa ser asumidos por Él -no importa si lo somos como trabajadores de primera o última hora- para participar responsablemente en la obra de la redención, cada cual con una misión personal que desempeñar; tan personal que, si se desatiende, deja tras de sí un vacío» (A. Cencini, Chiamati per essere inviati. Ogni vocazione è missione, Milano 2008, 70-71). 
llamada y la corresponsabilidad de la criatura en el proyecto de la salvación. Así, la vocación no es aquello que viene después, como si se tratase de un punto de llegada que sólo resulta accesible a unos pocos o al que arriban finalmente algunos virtuosos; el cristianismo es esencial e inmediatamente vocación, llamada, solidaridad con el hombre pecador y necesitado de salvación, impulso a formar parte activa del misterio de la redención. De modo que no se puede comprender auténticamente el cristianismo que se propone sin considerar esta solitud vocacional; porque al margen del descubrimiento de la propia vocación no puede darse una plena adhesión creyente. La vocación, en síntesis, es aquello que permite nacer y crecer la fe, ya que ser cristiano es en sí ser llamado y enviado, ser salvado en cuanto involucrado en la tarea de la salvación de los otros.

\section{Modalidades de acción}

La vocación, tanto en la catequesis como en la propuesta más amplia de la fe, ha de situarse, por ello, al comienzo del camino creyente; no sólo forma parte del kerigma, sino que hace crecer la fe. Tal vez podríamos hablar de un kerigma vocacional que expresa la esencia de la fe y muestra que la vocación forma parte de la misma. Vamos a tratar de sintetizarlo refiriéndonos a una serie de semillas vocacionales que han de ser sembradas-cultivadas en el hombre con paciencia y transparencia:

-Tu vida es preciosa, es algo grande y hermoso, que no mereces y jamás habrías podido conquistar.

-De hecho, procede de Otro, de Dios, Voluntad Buena que te ha preferido a la nada. Si procede de Dios, entonces no eres fruto de la casualidad, sino que existes dentro de un proyecto inteligente-amante como criatura amada, luego también libre y responsable del don recibido.

-Precisamente porque ese don procede de Otro, te abre a los otros, a imagen de aquel Dios que te ha creado a su imagen y semejanza, expresión única, singular e irrepetible de Él, llamado a realizarte según un proyecto pensado ex profeso para ti.

-Aunque más allá de toda auto-referencialidad. Alcanzarás la plena realización cuando te preocupes responsablemente de los otros, serás imagen acabada de Dios cuando el otro cuente para ti más que tú mismo, serás feliz cuando vivas en plenitud el don de ti mismo; de lo contrario, serás un triste boceto, encerrado y replegado sobre ti mismo, una caricatura de tu persona, una ficción existencial (tal vez parecido a esas caricaturas que ya has podido ver caminando por ahí).

-Así pues, eres libre de elegir aquello que quieras ser, pero recuerda: no eres libre de huir de esta gramática de la vida profundamente radicada en ti, o de ese proyecto inteligente y amante del que eres expresión; tú también estás 
llamado a ser inteligente y amante, responsable y generoso, agradecido y agraciante. A menos que prefieras ser una caricatura... ${ }^{16}$

\section{DISCERNIMIENTO VOCACIONAL}

Volviendo al ámbito pedagógico, otro elemento de novedad reside en el modo como se entiende en la actualidad el discernimiento vocacional. En este sentido, no nos interesan los criterios para el discernimiento en sí, sino adoptar el punto de vista del protagonista, de su significado y papel.

Durante mucho tiempo, el protagonista del discernimiento era el animador vocacional, y sólo después aquel que se encontraba en el camino vocacional. Lo que se espera hoy del animador vocacional es que sepa no sólo cómo hacer el discernimiento, sino acompañar al joven para que sea él mismo quien haga un discernimiento de sí y de la propia vocación. Este es el tipo de animador vocacional que necesitamos en la actualidad: capaz de educar para el discernimiento, es decir, para que el creyente se arriesgue a decidir en libertad, sabiendo que para ello no puede tener todas las certezas, sino que ha de aprender a fiarse y confiarse, a sustituir el cálculo, a la hora de decidir, por una respuesta confiada a Otro.

Si la crisis vocacional es también, y en gran medida, crisis de la capacidad de elección, la tarea más urgente del animador es la de poner a la persona en condiciones de tomar una decisión, sin sustituir su conciencia y juicio, sino ayudándola a dotarse de una sensibilidad vocacional que le consienta elegir en libertad y responsabilidad, como acto de amor ${ }^{17}$. El mismo título del próximo Sínodo de los Obispos se refiere precisamente a los jóvenes y su «discernimiento vocacional», señalando que es una tarea que ante todo les corresponde a ellos.

\section{Modalidades de acción}

Así pues, y atendiendo al ámbito pedagógico, el camino de la opción vocacional debe consistir en un aprendizaje sobre la capacidad de discernimiento, y más concretamente, en un entrenamiento progresivo en la toma de decisiones, en un aprendizaje para «elegir lo que es bueno, lo que es perfecto y agrada a Dios», para apostar por la Palabra de Dios, para no pretender fundar -por una parte- una opción como la vocacional en la garantía de las propias capacidades percibidas como respuesta a la aspiración a un camino que se

16. Cf. A. Cencini, Confermati o congedati? La cresima come sacramento vocazionale, Milano 2014, 158-160.

17. Esta es la línea que sigue, aunque sea en otro contexto, Amoris laetitia (en particular el n. 37). 
prefiere, y para no rendirse inmediatamente -por otra- frente a la constatación de las exigencias de la vocación cristiana y su requerimiento sobre las propias fuerzas ${ }^{18}$.

\section{El ministerio del acompañamiento y el discernimiento}

En una sociedad a-decisional como la nuestra, que no sólo no anima a optar, sino que declara imposibles las opciones que se hacen para toda la vida, esta educación para la capacidad de elección resulta un objetivo fundamental. Para la Iglesia implica la presencia de hermanos y hermanas capaces de desempeñar un ministerio específico con una preparación adecuada: el ministerio del discernimiento. ¡Cuánta necesidad tiene la Iglesia de este ministerio!

Lo que sucede es que este ministerio -que exige procurar tiempos específicos y oportunos para la dirección espiritual-no siempre suscita entusiasmo en el clero, tan requerido por mil tareas y preso de ciertos problemas de identidad y misión. De hecho, la dirección espiritual y, junto a ella, un itinerario de aprendizaje sobre la capacidad de discernir, generaría la posibilidad de una relación personal, que es condición fundamental para la tarea de la animación vocacional.

Por ello se advierte hoy la necesidad de sumar a los laicos a procesos de formación que presten particular atención a las parejas/familias y al valor de las figuras femeninas. $Y$ esto puede ser un gran recurso educativo.

\section{UNA IGLESIA TODA MINISTERIAL Y MADRE DE VOCACIONES}

La idea de una Iglesia que es madre de vocaciones no es un modo de hablar, sino de señalar la apertura de interesantes perspectivas en torno al modo de entender y ejercer la pastoral vocacional. Veamos al menos tres sentidos.

El primero. No es una novedad absoluta, pero desde hace un cierto tiempo se está tratando de proponer la pastoral vocacional a través de iniciativas extraordinarias, tanto clásicas (semanas vocacionales, grupos de oración vocacional, lectio divina, ejercicios espirituales vocacionales, campamentos vocacionales...) como más originales o innovadoras: tiempos dedicados a la experiencia de vida en común mediante un estilo de vida genuinamente cristiano, centrado en torno a la Palabra, la vida fraterna y el servicio (sin dejar de lado la propia responsabilidad en el estudio o el trabajo); diversas experiencias de anuncio en tierras de misión o experiencias de servicio y voluntariado (desde itinerarios propedéuticos a la elección de vida). Además

18. Cf. los llamados "abortos vocacionales» de Nuevas vocaciones para una nueva Europa, 35a. 
de estas iniciativas se viene insistiendo en la necesidad de insertar-integrar la pastoral vocacional dentro de la pastoral ordinaria. En Nuevas vocaciones para una nueva Europa se decía que había que vocacionalizar toda la pastoral, de modo que toda homilía, administración de los sacramentos, celebración eucarística, lectio, catequesis, devoción... que no sea vocacional no puede considerarse cristiana.

Esta extensión de la pastoral vocacional a toda la pastoral lleva aparejada otra apertura que va en la línea de la totalidad: el animador vocacional no puede identificarse simplemente con aquella persona que recibe un encargo oficial, sino que, de algún modo, somos todos los llamados a ser animadores vocacionales. Ser mediación de Aquel que llama, o preocuparse del camino de quien está en busca de la propia vocación, constituye un punto de llegada, el cumplimiento en grado máximo de lo que significa ser llamado. El llamado se convierte naturalmente en un llamante, de lo contrario estaría traicionando la propia vocación o dejaría de ser llamado.

La tercera apertura se refiere a la idea misma de vocación: que no puede coincidir solamente con la de especial consagración, presbiteral o religiosa, sino que afecta a todo tipo de estado de vida donde el creyente reconoce la llamada de Dios sobre su persona y un proyecto que ha de desplegarse a lo largo de todo el arco de la vida. Lo que se encuentra cada vez más en crisis es el hecho mismo de sentirse llamado por Dios a una determinada misión, cualesquiera que ella sea. Se encuentra en crisis la idea misma de vocación, de vocación cristiana, de concepción de la vida como respuesta a un requerimiento que procede de lo alto, la idea de responsabilidad frente a un don recibido. Por ello, no sólo se encuentra en crisis la vocación al presbiterado o a la consagración religiosa, sino la vocación al matrimonio, al compromiso político y social, la vocación a diversos ministerios según la necesidad del lugar en que se está, a la opción profesional como expresión de los propios valores cristianos e instrumento de testimonio y anuncio. Dicho esto, parece que sea precisamente esa la perspectiva que pretende adoptar el próximo Sínodo de los Obispos al asumir la temática del «discernimiento vocacional» de los jóvenes: el sentido de esta expresión coincide con el de una apertura vocacional amplia a todas las vocaciones, tratando así de entender cómo ayudar al joven a discernir como creyente la propia llamada, cualesquiera que ella sea.

\section{Modalidades de acción}

\section{En la Iglesia o crecen todos o ninguno}

Hay quien teme que esta ampliación de la idea de vocación acabe por dañar la pastoral de la vocación presbiteral. En realidad, no es así: promoviendo la idea de las diversas vocaciones y llevando a cabo una pastoral vocacional efectiva y totalmente abierta a todas las vocaciones se genera un 
humus propicio, una tierra buena, una cultura (considerada en sus tres fundamentos: mentalidad, sensibilidad y praxis) ${ }^{19}$ vocacionalmente fecunda, en la que podrán florecer fácilmente las vocaciones de especial consagración, a la vida sacerdotal y religiosa. No hemos de volver atrás espoleados por ese miedo (o angustia vocacional) vinculado a una visión eclesiológica ya superada en tiempos del Concilio y totalmente ineficaz en el plano pedagógico. Además, la historia nos dice que en la Iglesia o crecemos todos juntos o no crece ninguno.

Esta es la buena noticia, el anuncio gozoso que dar a toda persona con que nos encontremos: jaún hay lugar! «Tu» lugar te espera (Jn 14, 2-3) y no debes hacer nada para merecerlo: es una invitación que te precede, que te sorprende, que te supera. Es un lugar que sólo tú puedes ocupar, hecho a tu medida: si no respondes a tu llamada, nadie podrá ocupar tu puesto. Además, es el Señor quien viene a buscarte allá donde te encuentres, en «las plazas o las calles de la ciudad» (Lc 14, 21), sin importar que seas pobre, lisiado, ciego o cojo, joven o viejo. No importa. Porque Él te ha llamado primero (1 Jn $4,10)$ y es Él quien te hará capaz de realizar lo que sueña para ti, al servicio de la Iglesia y de la humanidad. Este es el anuncio.

Apostemos por la importancia de una pastoral vocacional unitaria y de comunión, evitando trabajar cada uno en solitario por el propio ámbito (seminario o instituto religioso o de vida consagrada).

La comunidad cristiana que se encuentra inmersa en el mundo no es el destinatario final de cualquier tipo de vocación, sino el ámbito privilegiado en el que surge y crece cada una de las vocaciones. Por esta razón es preciso valorar todos aquellos fermentos de vida cristiana que ayudan a vivir una fe fresca y vital, ya sean movimientos de espiritualidad, grupos de oración y animación, asociaciones, comunidades de base (tan presentes hoy en la vida de la Iglesia)... todo aquello que ayude a la pastoral a ser generativa, tal y como hemos apuntado.

\section{Optimismo VOCACIONAL}

Estamos necesitados de un creyente audaz, que viva en plenitud la propia vocación y que haya entendido de verdad que realmente son todos los llamados y a todos ha de ofrecerse el servicio de un acompañamiento vocacional. De lo contrario permaneceremos en esa situación paradójica y contradictoria que contempla la reducción de la pastoral vocacional: todos son los llamados, pero pocos aquellos a quienes se dirige la invitación y oferta de la ayuda de un acompañamiento; muchos menos son los que perciben una llamada y

19. Sobre la cultura vocacional, puede consultarse mi obra ya citada Non contano $i$ numeri, 21-32. 
se ponen a la escucha; y poquísimos, cada vez menos, los que responden de algún modo. Corremos el riesgo de desembocar en la imagen del hombre sin vocación.

Si nos ponemos en el punto de vista de los que llaman, el proceso sería el siguiente: todos son llamados, pero pocos los llamantes; aún menos los llamantes capaces de acompañar y formar para el discernimiento vocacional.

Ciertamente esta visión dibuja una perspectiva negativa y más bien deprimente; sobre todo, al considerar los retrocesos que afectan a la vocación al estado sacerdotal; dando por hecho que la lógica de los números es la decisiva y nos es francamente hostil.

Pero ¿y si las cosas no fuesen así? Lo que quiero decir es que si nos referimos al número total de aquellos creyentes que han elegido darse a sí mismos al Señor y a los hermanos dentro de los diversos estados vocacionales que se contemplan dentro de la Iglesia (por tanto, sobre todo como sacerdotes, pero también como consagrados, tanto en las diversas formas tradicionales como en las nuevas y variadas formas de consagración) podríamos concluir que se trata de un número que es, con certeza, más elevado que nunca. La tendencia vocacional es positiva, a pesar de las apariencias negativas y más allá de las previsiones lúgubres de aquellos que anuncian prácticamente el fin. La escasez no es tan negativa como muchos pintan o como tal vez sentimos todos dentro de nosotros. Los carismas vocaciones no se encuentran en crisis ${ }^{20}$. Resulta extraño que no se preste atención a este fenómeno del crecimiento. Que tal vez es signo de la naturaleza de aquella pequeña semilla que es la vocación, la más pequeña de todas las semillas, casi invisible y, sin embargo, dotada de una fuerza inaudita que la hace crecer y convertirse en un árbol capaz de acoger a todos los pájaros del cielo. Y más aún cuando se la colma de atención, cuando se cuida con dedicación y respeto, con fidelidad y paciencia. De hecho, estos son los creyentes que creen, aquellos buenos samaritanos de la vocación que son los animadores vocacionales en una Iglesia que es, en definitiva, jtoda vocacional!

\section{CRITERIO Y PEDAGOGÍA VOCACIONAL}

Acabo con una breve historia -cuyo sentido va más allá del suceso simpático que presenta-, narrada por William Bausch, que no es teólogo ni animador vocacional, sino atento observador y narrador.

Cuando Jesús llegó al cielo, los ángeles estaban ansiosos por verlo después de llevar a cabo su misión en la tierra. Así que se reunieron para darle la bienvenida. Le hicieron un sinfín de preguntas acerca de su experiencia en la

20. Cf. a este respecto J. C. Matos, Pastorale vocazionale, una vita che parla: Vita consacrata 52 (2016) 321. 
tierra, sobre esa gran misión a la que apenas había dado comienzo durante su estancia entre los hombres. En un momento determinado de la conversación, uno de los ángeles le preguntó: "¿A quién has confiado la responsabilidad de continuar después de ti ese gran trabajo?». Jesús respondió: "¡Se lo he confiado a un pequeño grupo de hombres y mujeres que me aman!». Los ángeles quedaron sorprendidos y desconcertados ante estas palabras, y uno le replicó: «¿Y ya está? ¿Y si fallan?». Entonces Jesús respondió: «No tengo otros planes» ${ }^{21}$.

He aquí el único y verdadero criterio vocacional del que deriva la única y verdadera pedagogía vocacional, como método y fin: el amor por el Señor que vive un pequeño grupo de hombres y mujeres. $\mathrm{O}$ dicho de otro modo: ¡Donde hay amor, el número es lo de menos! 